\title{
Cognitive changes after acute tryptophan depletion: what can they tell us? ${ }^{1}$
}

Serotonin (5-hydroxytryptamine, 5-HT) is known to play a role in a wide variety of functions including: mood, anxiety, sleep, aggression, sexual function and cognitive function. In the past decade, the sudden interest in acute amino acid depletion paradigms has stimulated the interest in studying the function of 5-HT in man in vivo. In particular, investigating the association of experimentally lowered 5-HT with cognition by measuring the influence of acute tryptophan depletion (ATD) on performance, and in some cases applying ATD as a challenge test using cognition as disease surrogate marker, have recently become popular. The crucial questions, 'what can this method tell us about cognitive function in health and disease?' and 'what can ATD-induced cognitive changes tell us about health and disease?' can only be answered after first considering basic assumptions about the method. These pertain to the derived questions, 'is ATD a serotonergic manipulation?', 'is the placebo used in ATD an inactive treatment?'. Also, 'are there specific cognitive markers of ATD?'. After a brief consideration of these issues, we will focus on the more clinical issues addressing the question whether ATD can be used as a challenge test, to indicate serotonergic vulnerability, using cognitive functions as surrogate measures of disease in particular.

\section{COGNITIVE EFFECTS OF ATD IN NORMAL VOLUNTEERS}

There is ample evidence showing 5-HT to be involved in cognitive functioning, particularly learning, memory and attention processes. In healthy subjects impaired long-term memory following ATD, including deficits in learning and memory consolidation has been reported (Park et al. 1994; Riedel et al. 1999; Rogers et al. 1999; Schmitt et al. 2000; Rubinsztein et al. 2001; Klaassen et al. 2002; McAllister-Williams et al. 2002; Harrison et al. 2003). In contrast, improvements in focused attention and executive function (Coull et al. 1995; Schmitt et al. 2000; Murphy et al. 2002) have also been reported after ATD.

\section{IS ATD A SPECIFIC SEROTONERGIC MANIPULATION?}

Serotonin's precursor molecule, tryptophan (TRP), is an indole-based essential amino acid. TRP is transported from the blood through the blood-brain barrier (BBB) into 5-HT neurons and is there transformed into 5-HT in a two-step enzymatic process (Azmitia, 2001). First, TRP is hydroxylated by tryptophan hydroxylase (TPH). For this process oxygen is needed as well as the co-factor tetrahydrobiopterin $\left(6 \mathrm{R}-\mathrm{BH}_{4}\right)$. The hydroxylated product, 5-hydroxy-tryptophan (5HTP) is converted into 5-HT by aromatic amino acid decarboxylase (AAAD). The first step in this pathway is the rate-limiting step (Eccleston et al. 1965). TPH is predominantly, if not uniquely, found in terminals of the raphe system, that is, in 5-HT neuron terminals (Kuhar et al. 1972). Under normal physiological conditions, TPH is thought to be $50 \%$ saturated with tryptophan (Young \& Gauthier, 1981) and 75\% with oxygen. Decreasing tryptophan levels can decrease 5-HT synthesis or turnover in rats (Biggio et al. 1974; Gessa et al. 1974), primates (Young et al. 1989) and humans (Nishizawa et al. 1997; Carpenter et al. 1998). Besides neurochemical evidence as listed above, behavioural evidence of ATD effects appear consistent with the view that ATD's effects indicate acute lowering of brain 5-HT neurotransmission. Furthermore, ATD's effects appear to be specific

\footnotetext{
${ }^{1}$ Address for correspondence: Dr Wim J. Riedel, GlaxoSmithKline, Translational Medicine \& Technology, Addenbrooke's Centre for Clinical Investigation, Hills Road, Box 128, Cambridge CB2 2QQ.
} 
for the depletion of tryptophan. Direct comparison of ATD with lysine depletion showed that the mood and memory effects of ATD did not manifest after depleting lysine, an arbitrarily chosen other essential amino acid (Klaassen et al. 1999a). This seems to rule out the hypothesis of protein synthesis inhibition, which would predict low mood and memory impairment as a result of simply leaving out any amino acid from a balanced mixture thereby hampering protein synthesis. Furthermore, that study also pointed out that ATD was the active condition to impair mood and memory, rather than that the balanced placebo mixture was the active condition that improved mood and memory. This was further substantiated by a study in which it was shown that delayed memory performance after placebo was unchanged relative to a baseline measurement, whereas $5 \mathrm{~h}$ after ATD performance was impaired, both relative to placebo and relative to baseline performance (Schmitt et al. 2000). That study also ruled out the hypothesis of ATD-induced impairment of memory consolidation post-learning, i.e. recall/recognition of material learned just before administration of the amino acid drink, was not affected by ATD. In another recent direct comparison study, it was shown that in the same sample of subjects, ATD exclusively impaired memory consolidation, while acute tyrosine/phenylalanine depletion impaired working memory performance, thus further establishing the specificity of ATD effects and also those of the cognitive effects of the highly similar acute depletion of tyrosine and phenylalanine, presumably modelling a state of lowered dopaminergic function (Harrison et al. 2003).

\section{ATD AS A CHALLENGE TEST FOR UNIPOLAR AND BIPOLAR DEPRESSION}

The best known phenomenon in ATD studies is that of its mood lowering effect, which occurs exclusively in subjects considered vulnerable for depression. These include most typically remitted depressed patients and healthy first-degree relatives of patients with major depression. Interestingly within the former group, those previously treated with selective serotonin re-uptake inhibitors (SSRIs) respond strongest to ATD whereas those treated with noradrenergic antidepressants respond with a mood-lowering response to catecholamine depletion rather than to ATD (Booij et al. 2002, 2003). Similar studies using cognitive measures have hardly been applied. The first of its kind showed that ATD impairs memory consolidation in all healthy individuals, irrespective of whether they have a family history of major depression $(\mathrm{FH}+)$ (Riedel et al. 1999). Recently, two such studies have been carried out using cognitive measures in the ATD paradigm. Sobczak et al. (2002a) studied the cognitive responses to ATD of healthy first-degree relatives of patients suffering from bipolar depression. A further distinction was made between relatives of bipolar disorder (BD) type I and type II patients respectively. In brief, the study showed that cognitive responses to ATD distinguished between first-degree relatives and controls. This pertained especially to the finding that ATD improved the response speed in the Tower of London planning task in controls, whereas it impaired the response speed in $\mathrm{FH}+$ especially in first-degree relatives of BD type I patients. The relevance, albeit an effect of small magnitude, is further confirmed by the finding that healthy first-degree relatives of bipolar type I disorder patients performed significantly slower than controls on this measure at baseline. The memory consolidation impairment effect of ATD was again replicated in this study, but it did not discriminate between FH + and control groups (Sobczak et al. 2002a). These results suggested a 5-HT mediated frontal lobe dysfunction as a biological surrogate marker of BD type I (Owen et al. 1990; Damasio, 1994; Elliott et al. 1997; Dagher et al. 1999; Murphy et al. 1999; Rubinsztein et al. 2000). Furthermore, these measures can also be used as surrogate measures of disease to indicate change of status in most cases before clinical signs are apparent. ATD effects observed in the control subjects by Sobczak et al. (2002a) resembled those previously reported (Park et al. 1994; Coull et al. 1995; Riedel et al. 1999; Schmitt et al. 2000; Rubinsztein et al. 2001; Murphy et al. 2002). The application of neurotransmitter challenge tests, such as ATD, has led to the conclusion that 5-HT is involved in bipolar disorder and thus there is indeed evidence for a rationale for 5-HT drugs in the treatment of BD (Sobczak et al. 2002b). 


\section{ATD IN NEURODEGENERATION: AGEING AND ALZHEIMER'S DISEASE}

An obvious therapeutic area for ATD to use as an experimental medicine model, given its specific effects on memory consolidation, is that of neurodegenerative diseases that may involve the serotonergic system. To be considered mainly are Alzheimer's disease (AD) and methylenedioxymethamphatamine (MDMA)-induced neurotoxicity. In AD, 5-HT dysregulation is reported separately or in conjunction with that of the cholinergic system, due to interactions at the receptor level, in particular in septo-hippocampal cholinergic neurones as well as in cholinergic neurones from the nucleus basalis to the cortex and the amygdala (Buhot et al. 2000). In a recent study by Porter et al. (2003) AD patients were administered ATD and their cognitive responses were compared with those of age-matched controls. No specific differences were found with respect to cognitive responses to ATD between the AD and control groups. However, the observed effects of ATD both in the normal aged and in the AD groups seemed to differ from those seen in healthy young volunteers. An impairment of performance on the backward digit span was observed after ATD in both groups. Such an impairment may well underlie other memory deficits induced by ATD, such as the observed ATD-induced impairment in the Paired Associates Learning test (Porter et al. 2003). However, no ATD-induced impairments were found on the Rey Auditory Verbal Learning Task or on the Rey Visual Design Learning Test. Ultimately, this could mean that memory consolidation impairment, although a sensitive indicator of acute tryptophan depletion, is not a relevant state marker of 5-HT, at least not for AD. Previously, the same group (Porter et al. 2000) reported on the basis of exactly the same groups of AD patients and healthy controls, that using the 3-MSE, an extended version of the Mini-Mental State examination (MMSE) scored on a scale of 1-100, AD patients responded to ATD by an impairment of performance on that scale, whereas elderly controls did not. Porter et al. (2003) noted that this may reflect a ceiling effect on this scale in the elderly control group. We, therefore, remain with the fact that this was hitherto the first and only study to investigate serotonergic vulnerability of AD patients using ATD. It can also be said that group sizes of 16 are fairly small given the heterogeneity inherent in AD. Further research seems highly desired to clear these matters.

\section{ACQUIRED NEURODEGENERATION: SEROTONERGIC VULNERABILITY ASSOCIATED WITH MDMA-USE}

Other evidence for ATD as a sensitive in vivo probe of serotonergic neurodegeneration may come from studies in former users of ecstasy. Long-lasting degeneration of long serotonergic fibres is seen after MDMA-use in animal studies (Ricaurte et al. 2000) and may also occur in human users (McCann et al. 1998, 2000; Reneman et al. 2001). These indirect observations of potential neurotoxicity are thought to underlie the overtly observed impairments of memory and mood in abstinent MDMA-users. More specifically it has been hypothesized that ecstasy users 'display cognitive deficits in tasks predominantly sensitive to temporal lobe dysfunction', but no deficits in most tasks sensitive to prefrontal functioning (Fox et al. 2002). This dissociation might be related to a predominant physiological role of the serotonin system for mnemonic processes, as has been suggested by ATD studies (Riedel et al. 2002). However, it may also be related to a particular vulnerability of the hippocampus and parahippo-campal regions to the neurotoxic effects of ecstasy (Gouzoulis-Mayfrank et al. 2003). Hence, ATD may be a model of the serotonergic depletion observed after MDMA use. A recent report comparing the metabolic and cognitive responses to ATD of former MDMA users showed that altered tryptophan levels, as well as memory, were the most sensitive markers of ATD's effects in ex-users of MDMA (Curran \& Verheyden, 2003). Furthermore, these measures were related in such a way that altered metabolism of tryptophan in ex-users may reflect pre-morbid differences in their 5-HT function and hence serotonergic vulnerability (Curran \& Verheyden, 2003). 


\section{CONCLUDING REMARKS}

ATD has been used to describe vulnerabilities for several serotonergically mediated manifestations of cognitive dysfunctions. These have been illustrated by commenting on recently described studies in the realm of depression and neurodegeneration. It should be noted however, that the findings may apply to a much wider domain of psychosomatic diseases bridging several therapeutic areas. For example, a high proportion of cancer and hepatitis $\mathrm{C}$ patients receiving immune-based therapy with the cytokine interferon-alpha, develop symptoms of depression that are indistinguishable from those found in major depressive disorders (Capuron et al. 2002). The mechanism is poorly understood and could either lead to low tryptophan via reduced appetite due to cytokine treatment, or tryptophan depletion by the cytokine-mediated induction of indoleamine 2,3-dioxygenase (IDO), the enzyme that accelerates the catabolism of tryptophan, or both (Capuron et al. 2002). Antidepressant treatment could improve these patients' conditions, by preventing the occurrence of depressive symptoms and by improving compliance with interleukin therapy. Therefore, a paradigm such as ATD with which it can be predicted pre hoc whether patients will be prone to these undesired psychological side-effects of interleukin treatment would be of considerable clinical benefit. In a different group of cancer patients suffering from carcinoid tumours in the gastrointestinal tract, which are known probably to cause a prolonged state of tryptophan depletion (Russo et al. 2003), a pattern of cognitive performance was observed that did not resemble the pattern observed in depression, but rather consisted of improved measures of focused attention, similar to the effects of ATD previously described in healthy volunteers (Coull et al. 1995; Schmitt et al. 2000).

Furthermore, the many results reported from studies with ATD seem to suggest that the use of tryptophan as a dietary source may either just as well be used as a probe of serotonergic function, or may be used as a therapeutic nutritional intervention. The former has been demonstrated in an experiment using dietary tryptophan to investigate appetitive behaviours (Attenburrow et al. 2003). The latter has been demonstrated by means of an experimental treatment with a tryptophan-rich protein to enhance aspects of mood and cognition in stress-prone individuals (Markus et al. 2000).

Despite the fact that ATD has become an experimental method that appears to be useful in discovery processes associated with diagnosis and treatment of biological factors underlying psychiatric and psychosomatic diseases, some issues still exist. Several demonstrations that first-degree relatives of unipolar and bipolar depressed patients respond with mood changes to ATD exist (Benkelfat et al. 1994; Klaassen et al. 1999 b; Quintin et al. 2001; Sobczak et al. 2002c), but the results are not unequivocal, and an attempt to replicate this finding and to study its within subject test-retest reliability failed (Ellenbogen et al. 1999).

More studies are needed to highlight the reliability and specificity of ATD effects and also to study dose-response effects. Multi-condition or group studies are highly recommended over headto-head comparisons of just ATD versus placebo. Furthermore, many more correlates of the metabolic effects of ATD ought to be considered for measurement. As determinants of the synthetic pathway of tryptophan, oxygen consumption and tetrahydrobiopterin could be used as markers of the conversion of TRP to 5-HTP. In addition, there are more than 14 active metabolites of tryptophan. Especially the NMDA agonist quinolinic acid and the NMDA antagonist kynurenic acid could modulate cognitive functions, especially memory consolidation by interaction with glutamate (Stone, 2001).

Finally, the predictive validity and hence the content validity of ATD-induced responses as indices of serotonergic vulnerability now need to be studied by longitudinal follow-up of healthy individuals considered to be at risk for diseases in which 5-HT is thought to play a role.

WIM J. RIEDEL 


\section{REFERENCES}

Attenburrow, M. J., Williams, C., Odontiadis, J., Powell, J., van de Ouderaa, F., Williams, M. \& Cowen, P. J. (2003). The effect of a nutritional source of tryptophan on dieting-induced changes in brain 5-HT function. Psychological Medicine 33, 1381-1386.

Azmitia, E. C. (2001). Modern views on an ancient chemical: serotonin effects on cell proliferation, maturation, and apoptosis. Brain Research Bulletin 56, 413-424.

Benkelfat, C., Ellenbogen, M. A., Dean, P., Palmour, R. M. \& Young, S. N. (1994). Mood-lowering effect of tryptophan depletion. Enhanced susceptibility in young men at genetic risk for major affective disorders. Archives of General Psychiatry 51, 687-697.

Biggio, G., Fadda, F., Fanni, P., Tagliamonte, A. \& Gessa, G. L. (1974). Rapid depletion of serum tryptophan, brain tryptophan, serotonin and 5 hydroxyindoletic acid by a tryptophan-free diet. Life Sciences 14, 1321-1329.

Booij, L., Van der Does, A. J. W. \& Riedel, W. J. (2003). Monoamine depletion in psychiatric and healthy populations: review. Molecular Psychiatry 8, 951-973.

Booij, L., Van der Does, W., Benkelfat, C., Bremner, J. D., Cowen, P. J., Fava, M., Gillin, C., Leyton, M., Moore, P., Smith, K. A. \& Van der Kloot, W. A. (2002). Predictors of mood response to acute tryptophan depletion. A reanalysis. Neuropsychopharmacology 27, 852-861.

Buhot, M. C., Martin, S. \& Segu, L. (2000). Role of serotonin in memory impairment. Annals of Medicine 32, 210-221.

Capuron, L., Hauser, P., Hinze-Selch, D., Miller, A. H. \& Neveu, P. J. (2002). Treatment of cytokine-induced depression. Brain Behavior and Immunology 16, 575-580.

Carpenter, L. L., Anderson, G. M., Pelton, G. H., Gudin, J. A., Kirwin, P. D., Price, L. H., Heninger, G. R. \& McDougle, C. J. (1998). Tryptophan depletion during continuous CSF sampling in healthy human subjects. Neuropsychopharmacology 19, 26-35.

Coull, J. T., Sahakian, B. J., Middleton, H. C., Young, A. H., Park, S. B., McShane, R. H., Cowen, P. J. \& Robbins, T. W. (1995). Differential effects of clonidine, haloperidol, diazepam and tryptophan depletion on focused attention and attentional search. Psychopharmacology 121, 222-230.

Curran, H. V. \& Verheyden, S. L. (2003). Altered response to tryptophan supplementation after long-term abstention from MDMA (ecstasy) is highly correlated with human memory function. Psychopharmacology 169, 91-103.

Dagher, A., Owen, A. M., Boecker, H. \& Brooks, D. J. (1999). Mapping the network for planning: a correlational PET activation study with the Tower of London task. Brain 122, 1973-1987.

Damasio, A. R. (1994). Descartes' Error. Emotion, Reason and the Human Brain. Papermac, MacMillan Publishers: London.

Eccleston, D., Ashcroft, G. W. \& Crawford, T. B. (1965). 5-hydroxyindole metabolism in rat brain. A study of intermediate metabolism using the technique of tryptophan loading. II. Applications and drug studies. Journal of Neurochemistry 12, 493-503.

Ellenbogen, M. A., Young, S. N., Dean, P., Palmour, R. M. \& Benkelfat, C. (1999). Acute tryptophan depletion in healthy young women with a family history of major affective disorder. Psychological Medicine 29, 35-46.

Elliott, R., Baker, S. C., Rogers, R. D., O'Leary, D. A., Paykel, E. S., Frith, C. D., Dolan, R. J. \& Sahakian, B. J. (1997). Prefrontal dysfunction in depressed patients performing a complex planning task: a study using positron emission tomography. Psychological Medicine 27, 931-942.

Fox, H. C., McLean, A., Turner, J. J., Parrott, A. C., Rogers, R. \& Sahakian, B. J. (2002). Neuropsychological evidence of a relatively selective profile of temporal dysfunction in drug-free MDMA ('ecstasy') polydrug users. Psychopharmacology 162, 203-214.

Gessa, G. L., Biggio, G., Fadda, F., Corsini, G. U. \& Tagliamonte, A. (1974). Effect of the oral administration of tryptophan-free amino acid mixtures on serum tryptophan, brain tryptophan and serotonin metabolism. Journal of Neurochemistry 22, 869-870.

Gouzoulis-Mayfrank, E., Thim, B., Rezk, M., Hensen, G. \& Daumann, J. (2003). Memory impairment suggests hippocampal dysfunction in abstinent ecstasy users. Progress in Neuropsychopharmacology and Biological Psychiatry (in the press).

Harrison, B. J., Olver, J. S., Norman, T. R., Burrows, G. D., Wesnes, K. A. \& Nathan, P. J. (2003). Selective effects of acute serotonin and catecholamine depletion on memory in healthy women. Journal of Psychopharmacology (in the press).

Klaassen, T., Riedel, W. J., Deutz, N. E. P., Van Someren, A. \& Van Praag, H. M. (1999a). Specificity of the tryptophan depletion method. Psychopharmacology 141, 279-286.

Klaassen, T., Riedel, W. J., Honig, A., Van Someren, A., Deutz, N. E. P. \& Van Praag, H. M. (1999b). Mood effects of 24-hour tryptophan depletion in healthy first degree relatives of patients with affective disorders. Biological Psychiatry 46, 489-497.

Klaassen, T., Riedel, W. J., Deutz, N. E. P. \& Van Praag, H. M. (2002). Mood congruent memory bias induced by tryptophan depletion. Psychological Medicine 32, 167-172.

Kuhar, M. J., Aghajanian, G. K. \& Roth, R. H. (1972). Tryptophan hydroxylase activity and synaptosomal uptake of serotonin in discrete brain regions after midbrain raphe lesions: correlations with serotonin levels and histochemical fluorescence. Brain Research 44, 165-176.

McAllister-Williams, R. H., Massey, A. E. \& Rugg, M. D. (2002). Effects of tryptophan depletion on brain potential correlates of episodic memory retrieval. Psychopharmacology 160, 434-442.

McCann, U. D., Szabo, Z., Scheffel, U., Dannals, R. F. \& Ricaurte, G. A. (1998). Positron emission tomographic evidence of toxic effect of MDMA ('Ecstasy') on brain serotonin neurons in human beings. Lancet 352, 1433-1437.

McCann, U. D., Eligulashvili, V. \& Ricaurte, G. A. (2000). $(+/-) 3,4-$ Methylenedioxymethamphetamine ('Ecstasy')-induced serotonin neurotoxicity: clinical studies. Neuropsychobiology $\mathbf{4 2}$ $11-16$.

Markus, C. R., Olivier, B., Panhuysen, G. E. M., van der Gugten, J., Alles, M. S., Tuiten, A., Westenberg, H. G. M., Fekkes, D., Koppeschaar, H. F. \& De Haan, E. E. H. F. (2000). The bovine protein alpha-lactalbumin increases the plasma ratio of tryptophan to the other large neutral amino acids, and in vulnerable subjects raises brain serotonin activity, reduces cortisol concentration, and improves mood under stress. American Journal of Clinical Nutrition 71, 1536-1544.

Murphy, F. C., Sahakian, B. J., Rubinsztein, J. S., Michael, A., Rogers, R. D., Robbins, T. W. \& Paykel, E. S. (1999). Emotional bias and inhibitory control processes in mania and depression. Psychological Medicine 29, 1307-1321.

Murphy, F. C., Smith, K. A., Cowen, P. J., Robbins, T. W. \& Sahakian, B. J. (2002). The effects of tryptophan depletion on cognitive and affective processing in healthy volunteers. Psychopharmacology 163, 42-53.

Nishizawa, S., Benkelfat, C., Young, S. N., Leyton, M., Mzengeza, S., de Montigny, C., Blier, P. \& Diksic, M. (1997). Differences between males and females in rates of serotonin synthesis in human brain. Proceedings of the National Academy of Sciences of the USA 94, 5308-5313.

Owen, A. M., Downes, J. J., Sahakian, B. J., Polkey, C. E. \& Robbins, T. W. (1990). Planning and spatial working memory following frontal lobe lesions in man. Neuropsychologia $\mathbf{2 8}$, 1021-1034.

Park, S. B., Coull, J. T., McShane, R. H., Young, A. H., Sahakian, B. J., Robbins, T. W. \& Cowen, P. J. (1994). Tryptophan depletion in normal volunteers produces selective impairments in learning and memory. Neuropharmacology 33, 575-588.

Porter, R. J., Lunn, B. S., Walker, L. L., Gray, J. M., Ballard, C. G. \& O'Brien, J. T. (2000). Cognitive deficit induced by acute tryptophan depletion in patients with Alzheimer's disease. American Journal of Psychiatry 157, 638-640. 
Porter, R. J., Lunn, B. S. \& O'Brien, J. T. (2003). Effects of acute tryptophan depletion on cognitive function in Alzheimer's disease and in the healthy elderly. Psychological Medicine 33, 41-49.

Quintin, P., Benkelfat, C., Launay, J. M., Arnulf, I., PointereauBellenger, A., Barbault, S., Alvarez, J. C., Varoquaux, O., PerezDiaz, F., Jouvent, R. \& Leboyer, M. (2001). Clinical and neurochemical effect of acute Tryptophan depletion in unaffected relatives of patients with bipolar affective disorder. Biological Psychiatry 50, 184-190.

Reneman, L., Booij, J., Majoie, C. B., Van Den Brink, W. \& Den Heeten, G. J. (2001). Investigating the potential neurotoxicity of ecstasy (MDMA): an imaging approach. Human Psychopharmacology, Clinical and Experimental 16, 579-588.

Ricaurte, G. A., Yuan, J. \& McCann, U. D. (2000). (+/-)3,4Methylenedioxymethamphetamine ('ecstasy')-induced serotonin neurotoxicity: studies in animals. Neuropsychobiology 42, 5-10.

Riedel, W. J., Klaassen, T., Deutz, N. E. P., Van Someren, A. \& Van Praag, H. M. (1999). Tryptophan depletion in normal volunteers produces selective impairment in memory consolidation. Psychopharmacology 141, 362-369.

Riedel, W. J., Klaassen, T. \& Schmitt, J. A. J. (2002). Tryptophan, mood and cognitive function. Brain, Behavior, and Immunity 16, 581-589.

Rogers, R. D., Blackshaw, A. J., Middleton, H. C., Matthews, K., Hawtin, K., Crowley, C., Hopwood, A., Wallace, C., Deakin, J. F. W., Sahakian, B. J. \& Robbins, T. W. (1999). Tryptophan depletion impairs stimulus-reward learning while methylphenidate disrupts attentional control in healthy young adults: implications for the monoaminergic basis of impulsive behaviour. Psychopharmacology 146, 482-491.

Rubinsztein, J., Rogers, R. D., Riedel, W. J., Mehta, M. A., Robbins, T. W. \& Sahakian, B. J. (2001). Acute dietary tryptophan depletion impairs affective shifting and delayed visual recognition in healthy volunteers. Psychopharmacology 154, 319-326.
Rubinsztein, J. S., Michael, A., Paykel, E. S. \& Sahakian, B. J. (2000). Cognitive impairment in remission in bipolar affective disorder. Psychological Medicine 30, 1025-1036.

Russo, S., Nielen, M. M., Boon, J. C., Kema, I. P., Willemse, P. H., De Vries, E. G., Korf, J. \& Den Boer, J. A. (2003). Neuropsychological investigation into the carcinoid syndrome. Psychopharmacology 168, 324-328.

Schmitt, J. A., Jorissen, B. L., Sobczak, S., van Boxtel, M. P., Hogervorst, E., Deutz, N. E. \& Riedel, W. J. (2000). Tryptophan depletion impairs memory consolidation but improves focussed attention in healthy young volunteers. Journal of Psychopharmacology 14, 21-29.

Sobczak, S., Riedel, W. J., Booij, L., Aan het Rot, M., Deutz, N. E. P. \& Honig, A. (2002a). Cognition following acute tryptophan depletion: differences between first-degree relatives of bipolar disorder patients and matched healthy control volunteers. Psychological Medicine 32, 503-515.

Sobczak, S., Honig, A., Duinen, M. v. \& Riedel, W. J. $(2002 b)$. Serotonergic dysregulation in bipolar disorders; a literature review of 5-HT challenge studies. Bipolar Disorders 4 347-356.

Sobczak, S., Honig, A., Nicolson, N. \& Riedel, W. J. (2002c). Effects of acute tryptophan depletion on mood and cortisol release in first-degree relatives of type I and type II bipolar patients and healthy matched controls. Neuropsychopharmacology 27, 834-842.

Stone, T. W. (2001). Kynurenines in the CNS: from endogenous obscurity to therapeutic importance. Progress in Neurobiology 64, $185-218$.

Young, S. N. \& Gauthier, S. (1981). Tryptophan availability and the control of 5-hydroxytryptamine and tryptamine synthesis in human CNS. Advances in Experimental and Medical Biology 133, 221-230.

Young, S. N., Ervin, F. R., Pihl, R. O. \& Finn, P. (1989). Biochemical aspects of tryptophan depletion in primates. Psychopharmacology 98, 508-511. 